\section{FATAL POISONING BY "META FUEL" TABLETS}

BY

\author{
D. RHYS LEWIS, M.D., F.R.C.P. \\ Honorary Physician
}

\author{
G. ALAN MADEL, M.R.C.S., L.R.C.P. \\ Honorary Anaesthetist
}

AND

\author{
JOAN DRURY, M.A., M.B., B.Ch. \\ Assistant Pathologist, Swansea General Hospital
}

Many cases of poisoning by "meta" tablets have been recorded in Continental literature. In Britain the first case of such poisoning was recorded by Willcox and Mitchell (1927), and later another by Miller (1928). Their patients made a complete recovery. On the Continent a few deaths from meta-poisoning have occurred. On account of the fatal issue in our case, and the opportunity of making a post-mortem examination, we felt it our duty to publish these notes.

Since the introduction of "meta" into domestic life our children's careless days may no longer be a joy but a sorrow. There is a real danger that a child may be ambushed on his inquisitive errands, for this product is supplied by the manufacturers in tablets attractive both in form and in colour. They may be easily mist.ken for the popular peppermint lozenge, and a child almost instinctively puts in his mouth anything which reminds him of a sweet. It is true that several attempts have been made to produce a tablet with a disagreeable taste and smell, but so far this has not been possible without diminishing the cheapness of the product and the quality of its combustion. A change in the colour of the tablet was suggested, but it was found that tablets of almost any hue attracted children just as much as its present white colour.

\section{Characteristics of Meta}

Meta is the trade name for the product produced by the polymerization of metacetaldehyde, and is imported into Britain from Switzerland, where the first cases of meta-poisoning were observed. Its activity is far greater than that of its isomer paraldehyde. It is supplied in the form of elongated tablets, usually about two inches long and half an inch thick, and has probably gained its present popularity because the tablet is solid, clean, easy to use as a source of fuel in picnics, etc., and lights only in contact with a flame. It burns without smoke, leaves no ash, and is insoluble in the majority of liquids except very feebly in chloroform and benzene. According to Gautier (1928) combustion of meta cannot produce any poisoning. It is not scheduled as a poison and its sale is unrestricted. The gardener has taken advantage of its poisonous character to kill slugs and snails, and the method of mixing it with bran has been responsible for the innocent slaughter of many of our wild birds. It is strange that the manufacturers in their leaflet state that "meta seems harmless to birds." It is slowly absorbed from the intestine, and by its poisonous action on the central nervous system it produces drowsiness and convulsions. The majority of the recorded cases of accidental poisoning by meta have been in young children, and most of the adult cases have been attempts at suicide. The fatalities have all occurred in the young.

\section{Case Report}

Our unfortunate patient was a boy aged $2 \frac{1}{2}$. So far as we could ascertain he swallowed one tablet only, at about 5.15 p.m. He told his nursemaid that it was not a nice sweet. About twenty minutes later he fell asleep for about an hour, and woke up crying, retching, and complaining of abdominal pain. At 6.45 p.m. he was seen by one of us (G. A. M.), and it was ascertained that a large dose of castor oil had been administered by the mother immediately after the child had swallowed the fuel, but it was mentioned that he had had a large bowel evacuation immediately before doing so. On endeavouring to pass a stomach tube the child vomited; the vomitus contained a few small pieces of fuel, and was practically odourless, apart from a very faint musty smell. Finally the stomach tube was passed successfully, and the stomach washed out with a solution of sodium bicarbonate. the washings containing a few small pieces of fuel. Following this treatment the child appeared relieved, and in about fifteen minutes later fell asleep.

He was seen again at about 8.30 p.m., and, apart from a few attacks of retching, seemed better. At 10 p.m. he woke up from a short sleep complaining of a return of abdominal pain, and had a convulsion which lasted about three minutes. His stomach was once more washed out, and half a pint of saline injected per rectum. He fell asleep again for about half an hour, and awoke with another convulsion, which lasted for five minutes. Convulsions now recurred every ten minutes or so until midnight, when the child lost consciousness completely and the convulsions increased in frequency and lasted for a longer period. Rectal saline was administered at intervals until 2 a.m., when the convulsions became almost continuous. Chloral, 10 grains, and potassium bromide, 20 grains, were given per rectum.

At 1.45 a.m. the child became very much worse, there being only a short interval between the convulsions. The teeth were clenched, risus sardonicus and opisthotonos occurred, and the legs were extended and rigid. The pupils were contracted, the temperature had risen from $98^{\circ} \mathrm{F}$. at 6.45 p.m. to $102.4^{\circ} \mathrm{F}$. at 2 a.m. The pulse rate was 130 and the respirations 42 . At 2.45 a.m. he was admitted to the Swansea General. Hospital. He was drowsy and was having frequent convulsions. His temperature was $104^{\circ} \mathrm{F}$. and the pulse 140 . The pupils were contracted. The limbs were rigid and the reflexes were present. Within a few hours of being admitted to hospital the convulsive attacks further increased in frequency and coma supervened.

In the absence of any known antidote, we emptied the stom:ach as rapidly as possible, administered chloral and bromide, and gave abundant drinks, especially milk. The child was also given one-tenth grain of apomorphine. All treatment was of no avail, and death occurred within thirtythree hours of swallowing the meta.

In the literature prognosis was said to hang on the suddenness of the appearance of symptoms, on the more or less frequent repetition of the convulsive attacks, and on the rapidity of the coma. When the epileptiform attacks occurred at intervals in spite of persistent coma the prognosis was good. The prognosis depended also on the manner of taking the meta. The more this was divided the greater the rapidity and the more serious the consequences. The chief feature to consider was how soon the spontaneous or provoked vomiting occurred. A case has been recorded where a woman swallowed the enormous dose of six tablets, vomited immediately, became gravely ill, but made a complete recoverý.

\section{Post-mortem Appearances}

The body was that of a normally developed male child. The skin was intensely pale, that of the face and soles of the feet having a lemon-yellow colour. The brain was congested, and in the white matter there were a number of minute petechial 
haemorrhages. The urea of a post-mortem specimen of cerebrospinal fluid was $108 \mathrm{mg}$. per $100 \mathrm{c.cm}$. The trachea was normal and the lungs showed areas of collapse and congestion. The tracheal and hilar glands were not enlarged. The heart showed dilatation of the right ventricle and auricle; the muscle was firm but pale, and there were numerous endocardial petechiae in the left ventricle. There were no pericardial haemorrhages, and the quantity and nature of the pericardial fluid were normal. No abnormality was present in the aorta or other vessels.

The oesophagus appeared normal; the stomach was empty and there were small patches of petechial haemorrhages in the mucosa, which was otherwise normal. The jejunum and upper part of the ileum was congested, and contained semi-solid bile-stained material. The lower part of the ileum was pale and contracted so as to admit the ball end of fine scissors with difficulty ; the contents consisted of a creamy-coloured odourless paste. The large intestine contained a small quantity of normal faeces. The liver was of normal size, very pale, and of a yellow colour, with patches of haemorrhage about one inch in diameter; the liver pattern was ill defined. The gall-bladder was distended with bile. The kidneys were pale, but there was no other microscopical abnormality. The bladder was empty. The thyroid, pancreas, suprarenals, and thymus were normal in appearance. Microscopical examination of the liver revealed intense fatty degeneration affecting all the liver cells, with zonal necrosis showing pyknotic nuclei and a complete disintegration of the cells, with extravasation of red blood cells into the liver tissue. As there was no excess of bile pigment the yellow colour of the liver presumably was due to fat. The kidneys showed normal glomeruli with swelling and desquamation of the tubular epithelium, and small areas of congested capillaries with red cells lying without the capillary wall. The contents of the lower ileum were submitted to further examination microscopically and chemically. The pasty material consisted of mucus with fine needle crystals which closely resembled those of a meta tablet when ground up in water. A portion of the material was heated in a sealed glass tube at $100^{\circ} \mathrm{C}$. for half an hour; a watery solution was then made, and this solution was examined for the presence of acetaldehyde by the iodoform and silver nitrate tests. Both tests gave a positive reaction, but the iodoform test was also positive for a normal stool treated in the same way; the silver nitrate test was negative for the normal stool. Unfortunately no urine was obtained, as the patient was incontinent.

\section{Conclusions}

Meta-poisoning has serious possibilities, with a medicolegal significance; for diagnosis may be difficult unless there are reasons to consider such poisoning. So long as its sale is unrestricted it may become the popular choice of the suicide or criminal. The packing of such a dangerous poison in frail cartons is not conducive to safety. Once the carton is opened the tablets may easily drop out and fall within the reach of young children.

To protect the child the public should be warned of meta's dangerous qualities, and the State should introduce measures for a safer distribution.

\section{BiblogRAPHY}

Belfrage, H. (1927). Acta Paediatr., Stockh., 6, 481. French, A. (1935). British Medical Journal, 2, 974.

Gautier, R. (1928). Bull. Soc. Pédiat. Paris, 26, 255

and Colomb, R. (1926). Rev. méd. Suisse rom., 66, 811.

Leschke, E. (1934). Clinical Toxicology, London.

Miller, R. (1928). Arch. Dis. Childh., 3, 292.

Petit, G., and Audistère (1933). Ann. Méd. lég., 13, 449.

Petr, and Marchand, L..(1935). Rev. neurol., 64, 873.

Stähelin, Michaud, and Zangger (1932). Schweiz. med. Wschr., 62, 674.

Vischer, A. (1935). Ibid., 65, 827.

Willcox, W. H., and Mitchell, C. A. (1927). Analyst, 52, 528.

Wolfer, P. (1927). Schweiz. med. Wschr., 57, 1144.

\section{Clinical Memoranda}

\section{Morphine and Chloroform in Liver Atrophy}

The following case seems to be of sufficient interest to be recorded.

\section{Case Report}

On September 21, 1938, a man aged 42 was admitted as a voluntary patient to the Royal Edinburgh Mental Hospital. He gave a history of morphine addiction of ten years' duration. A psychopathic state was the predisposing cause, and abdominal pain, appearing after operation for a perforated duodenal ulcer, was the precipitating cause of the addiction. He had been taking as much as 5 grains of morphine sulphate per day by injection, though for the past two years 2 grains was rarely exceeded. Whereas previously he had weighed over 10 st. in health, by the time he was admitted he weighed only $7 \mathrm{st} .4 \mathrm{lb}$. Previous history of jaundice was negative.

On the first day after admission he was given 1 grain of morphine. Thereafter he required only $1 / 4$ grain for three successive nights, while codeine phosphate was administered in gradually increasing doses as a substitute. The usual general measures were adopted, and in addition he was given 5 units of insulin three times daily, increased at the end of one week to ten units. Though the deprivation symptoms cleared up within a fortnight he continued to complain of vomiting and abdominal pain. He was found to have signs of pyloric stenosis, this being verified radiologically. A large dilated stomach, with abundance of fasting juice and with retention of barium for twenty-four hours, was found. An operation was performed by Mr. C. F. W. Illingworth, under chloroform and ether anaesthesia, with atropine $1 / 100$ grain premedication. A large inflammatory mass was found surrounding the pyloric antrum, and numerous enlarged glands along both curvatures. It was decided to perform a partial gastrectomy, and this was done, together with an end-to-side anastomosis. The operation lasted approximately one and a quarter hours. Not more than $1 \mathrm{oz}$. of chloroform was used for induction, and approximately $12 \mathrm{oz}$. of ether during the rest of the operation. On the same night an intravenous drip infusion was set up, and he received by this method about $1,500 \mathrm{c.cm}$. of a 5 per cent. glucose solution. This was then stopped, and on the second day rectal glucose saline was administered on three occasions. Sips of sterile water were allowed forty-eight hours after operation, and these were gradually increased in frequency and amount. The rectal salines were stopped on the third day. It was at this time that he was observed to be passing brownishred urine which contained large quantities of amino-acid and cholesterol crystals - the amino-acids recognized being leucine, tyrosine, and cystine. There was no bile and no blood. During the succeeding days he continued to pass these crystals in much the same quantities, although his general condition was well maintained. During the third and fourth days a slight lemon-yellow tinge of jaundice appeared on the skin and mucous membranes. The liver was neither tender nor reduced in size. Severe pain was complained of in the region of the wound, for which small doses of heroin and morphine were given. The temperature was normal throughout. The van den Bergh test gave a weak biphasic direct result. From the first, glucose with insulin 10 units twice daily was given in large quantities. During the second week a marked looseness of the bowels was found, the stools being normal in colour. All these signs have gradually disappeared and the wound has healed well. The patient is now on a normal diet, and the insulin has been stopped. He is putting on weight, being now 7 st. $10 \mathrm{lb}$., six weeks after operation.

\section{COMMENTARY}

The presence of amino-acids and cholesterol in the urine is conclusive evidence of liver destruction, and the amounts were such as to indicate extensive involvement. In spite of this the patient's general condition remained good 